UCRL-92023

PREPRINT

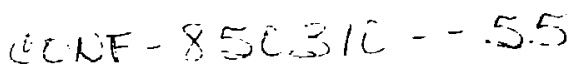

1

\title{
PLASMA ENGINEERING FOR MINIHARS: A SMALL COMMERCIAL TANDEM MIRROR REACTOR WITH OCTOPOLE PLUGS
}

L. J. Ferkins, B. G. Logan, R. B. Campbe11, R. S. Devoto, D. T. Blackfield, and B. H. Johnston,

This paper was prepared for subaittal to the

6th Topical Meeting on the Technology of Fusion Energy, San Francisco, California, March 3-7, 1985

April 3, 1985

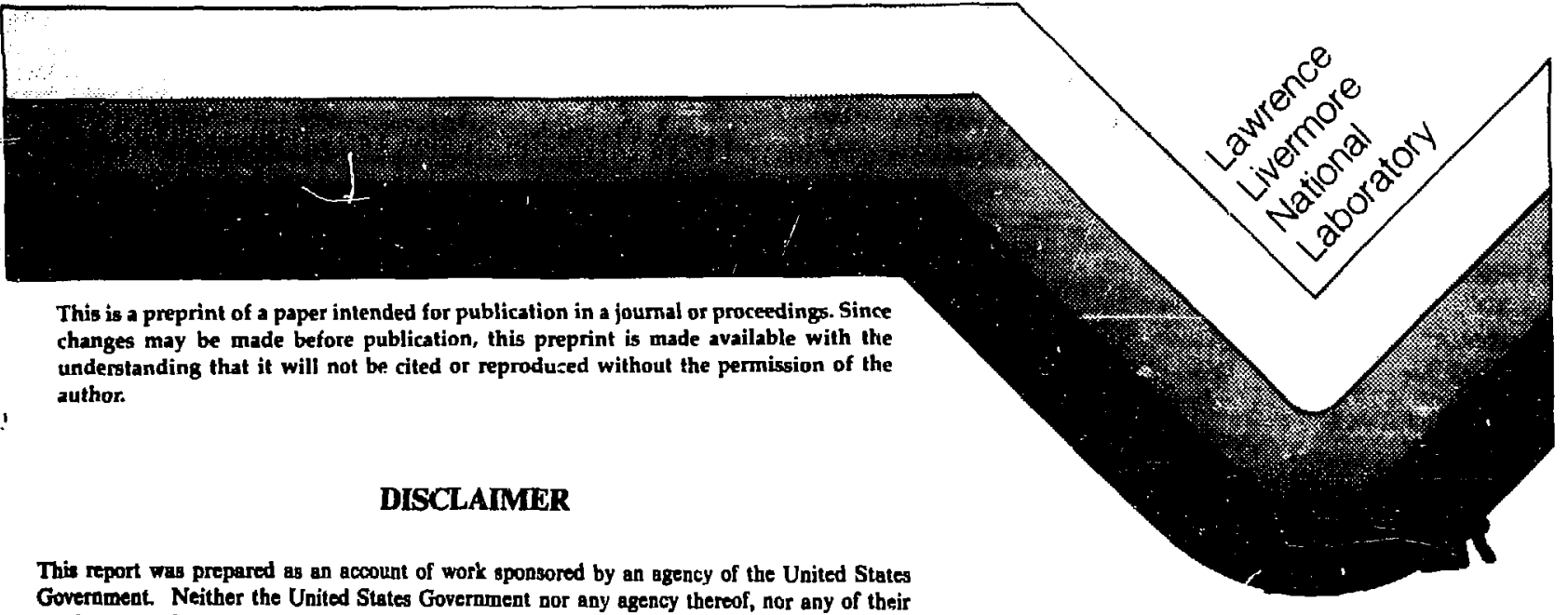

Government. Neither the United States Government nor any agency thereof, nor any of their employees, makea any warranty, express or implied, or assumes any legal liability or responsibility for the eccuracy, completeness, or uscfulness of any information, apparatus, product, or procesen disclosed, or represents that its use would not infringe privately owned rights. Referonece berein to any specific commercial product, process, of servico by trade name, trademark, manufacturer, or otherwise does not necessarily constitute or imply its endorsement, recommendation, or favoring by the United Statea Government of any agency thereof. The views and opinion of authors expresed berein do not necessarily state or reflect those of the United States Government or any agency thereof.

DISTR!DUTIYY OF TUIS OONUHENT IS UHLIMITEB

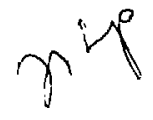


PLASMA ENGINEER ING FOR MIN IMARS: A SMALL COMGERCIAL TANDEM MIRROR REACTOR WITH OCTOPOLE PLUS*

L. J. Perkins, B. G. Logan, R. B. Campbel1, t R. S. Devoto, D. T. Blackfield, tt and B. H. Johnston Lawrence Livermore National Laboratory, University of California P.0. Box 5511 (L-644)

Livermore, California 94550

(415) 423-6012

\section{ABS TRACT}

With the employment of a novel octopole end plug scheme, we examine the plasma engineering design of HIN DMARS, a small compact fusion reactor based on the tandem mirror principle. With a net electric output of $600 \mathrm{MW}_{\mathrm{e}}$, MINIMARS is expressly designed for short construction times, factory built modules, and a pasaively safe blanket aystem. We show that the compact octopole/mantle provides several distinct improvements over the mare conventional quadrupole (yin-yang) end plugs and enables ignition to be obtained with much shorter central cell length. In thig way we can design economic small reactors wich will minimize utility financial risk and provide attractive alternatives to the conventional larger fusion plants encountered to date.

\section{INTRODUCT TON}

The Mirror Advanced Reactor Study (MARS), 1 the precursor of MINIMARS, was concerned with a relatively large $1200 \mathrm{NW}_{\mathrm{e}}$ commercial tandem mirror reactor with double quadrupole (yin-yang) end plugs. Although we took advantage of both the attractive reactor features of the tandem mirror concept and the potential of fusion for improved safety and environmental impact over fission, we concluded the Mars project with enhanced understanding of how we should fully exploit the intrinsic characteristics of the tandem mirror to achieve an optimum reactor design in terms of economics and utility attractiveness. Accordingly, coumencing in FY85, Lawrence Livermore National Laboratory, in partnership with the Fusion Engineering Design Center, the University of Wisconsin, TRW, Grumman Aerospace Corporation, Ontario

\footnotetext{
*Work performed under the auspices of the U.S. Department of Energy by the Lawrence Livermore National Laboratory under contract number W-7405-ENG-48.

†TRW Inc., LLNL, Livermore, CA 94550.

+t TRW Inc., FEDC, Oak Ridge, TN 37830
}

Hydro, Bechtel Group Inc., General Dynamic g/ Convair, and Argonne National Laboratory, is conducting a conceptual design of "MIN MARS", a $s$ mall commercial tandem mirror reactor with novel octopale end plugs.

We have adopted three basic objectives for MIN IMARS :

1. Plasma Engineering. A new concept for cumpact octopole plugs ${ }^{2}$ makes it possible to significantly $\mathrm{r}^{-}$- the size, weight, and cost of the end cell magnets relative to MARS and, thereby, attain central cell ignition in much smaller lengths. Accordingly, we are evaluating the plasma engineering issues underlying the octopole concept and performing a comparison with other novel stabilization approaches.

2. Reactor Sizes and Economics. There is increasing utility interest in small, modular power plants and MINIMARS can exploit the potential of the octopole plug concept to achieve small but economic reactors. Accordingly, we are:

(a) evaluating a point reactor design at $600 \mathrm{HW}_{\mathrm{e}}$ with short ( 23 year) construction times and factory-built modular construction, and (b) evaluating utility financial risk (total capital investment), growth system cost of electricity (mills/kWhr), and economy of scale of MIN IMARS plants ranging from 250 to $2400 \mathrm{KW}_{\mathrm{e}}$. In this regard, we will cont inue to make substantial use of the Tandem Mirror Systems Code Optimization Package (see below).

3. Safety, Environment, and Economics. With attention to system power density and judicious choice of materials, we can design for low afterheat, passively-safe shutdown, and blanket systems that sustain no damage from LOC/LOF accidents. Accordingly, we are making a afety an inherent part of the MIN IMARS design, thereby obviating the need for engineered, or active, safety systems 
and facilitating the reduction of the size of the "nuclear grade" envelope. This has the effect of simplifying considerably the plant external to the fusion power core.

\section{PHYSICS BAS IS OF MIN IMARS}

A cross section of the first baseline design of MIN LMARS at $600 \mathrm{HW}_{\mathrm{e}}$ is shown in Fig. I, thile a schematic of the plasma/magnet configuration is shown in Fig. 2. Also shown in Fig. 2 is the axial distribution of the magnetic field and plasms potential. As with MARs ${ }^{1}$ its predecessor, the axial pressure of the DT fuel iong in the simple solenoidal ( $23 \mathrm{~T}$ ) central cell is contained mainly by the $h$ igh field choke coils ( $26 \mathrm{~T}$ ) at each end. Similarly, nearly all the $3.5 \mathrm{MeV}$ fusion alpha particles are born mirror trapped in the central cell. The amg:.1 fraction $(<10 \%)$ of central cell ions which pitch angle scatter into che loss cone and pass into the octopole end cell, reflect off the positive plugging potential and return through the central cell. The magnitude of the potential peak $(>150 \mathrm{kV}$ relative to the central cell potential) reduces the central cell ion end loss sufficiently to allow fusion alpha heating to sustain residual central cell energy losses due to end cell trapping (gee below); i.e., the central cell is ignited.

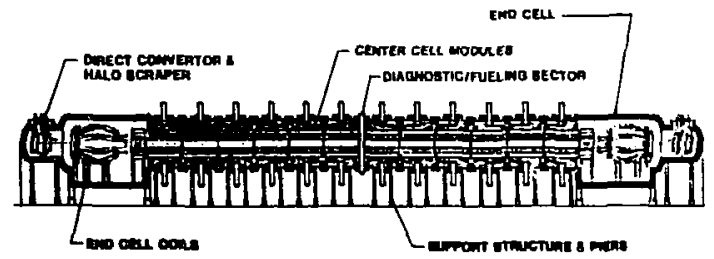

Fig. 1. The firat MINIMARS basel ine design at $600 \mathrm{MW}_{\mathrm{e}}$.

In addition to the potential peak, a "thermal barrier"l is required in the end cell to moderate electron heat concuction from the peak and, therefore, to reduce end cell heating power. A depression in the end cell ion density is formed by microstable "sloshing iong" fueled by a $475 \mathrm{kV}$ negative-ion neutra 1 beam source. Mirror-trapped hot electrons gustained by ECRH heating at the midplane of the sloshing ion distribution provide the required negative potential ( $-145 \mathrm{kV}$ relative to the central celi) of the thermal barrier (see Fig. 2). MHD stabilization of MINIMARS by means of the octopole coil and a hot electron mantle is discussed in a later section.

Many of the MINIMARS plasma confinement features are derived from past and present tandem mirror experiments at LLNL, especially the Tandem Mirror Experiment-Upgrade (TMX-U) ${ }^{3}$
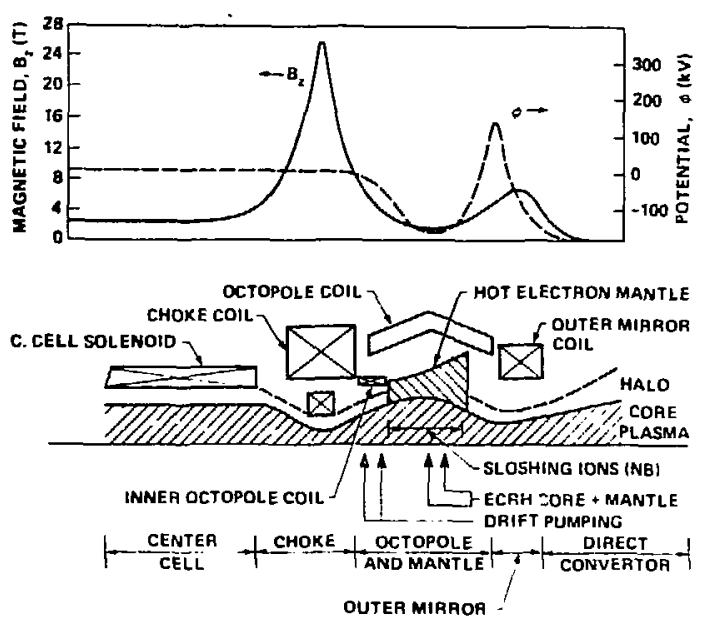

Fig. 2. Scheratic of the plasmg/magnet configuration of MIN IMARS with octopole end cells. An axial distribution of magnetic field and plasan potential is shown on the same scale.

and the Mirror Fusion Test Facility (MFTF-B), 4 In particular, our plasma modeling draws heavily on behavior observed in TMX-U namely: microstable sloshing ions with loss rates predicted by Fokker-Planck codes, enhanced thermal barrier formation with ECRH, reduction of ion end loss by potential plugging so that radial ion losses dominate, net electron current collection on end wall plates, and vacuum pumping by the plasma halo. Plans are now underway for TMX-U to test several MINIMARS-related features such as high-field choke coils, octopole coils, hot electron mantles, and drift pumps.

THE RATIONALE FOR OCTOPOLE COILS: THE IGNITION COND IT ION

The Mirror Advanced Reactor Study (MARS) 1 employed a quadrupole end cell magnetic configuration in the form of a complex double yin-yang magnet set with recircularizing transition coils. While providing a well-tested method of high beta MHD atabilization, quadrupoles have three disadyantages for tandem mirror reactor applications: (1) the end cell magnet configuration is complex and expensive; (2) the end cell plasma flux bundle is nonaxisymmetric with sttendant radial drift problems; and ( 3 ) the required central cell length for ignition is large making it difficult to achieve small reactors economically.

The last point is particularly important. The condition for ignition of a tandem mirror reactor is that the power deposited by fusion alpha particles in the central cell plasma must be greater or equal to all sources of power losa from this volume. Now passing central 
cell ions wich undergo collisional trapping in the end ceill betueen the potential peak and the choke coil magnetic field peak must be removed (or "pumped") at the rate at which they trap, otherwise the end cell would fill with trapped ions and the thermal barrier vould be destroyed. To provide this pumping ve configure "driftpump" coils above and belou the plasma in the end $c: 11$ and $e$ fect a resonance between the coil frequency and the bounce frequency of the trapped ions.l The resulting enhanced radial diffusion transports these ions to the unplugged halo plasms surrounding the core plasma, and they are owept to the grounded halo dumps at the ends of the machine. 1 The ion trapping rate (and thus drift pump loss rate) of ions in the end cell scales as the end cell plasma volume, the square of the end cell ion density, and the imverse of the central cell ion temperature to the three-halves pover. 1 Drift pumping of trapped ions in the end cell represents the major power $108 s$ mechanism from the central cell plasma (other losses such as axial ion losses and radiation losses are typically less than 107 of the total), thus we can represent the central cell ignition condition as

$r_{c}^{2} L_{c} P f_{\alpha} \geq c r_{e c}^{2} \operatorname{ec}^{n^{2}} \mathrm{ec}^{T_{c}^{-3 / 2}}+s$

where $I_{c}, L_{c}, I_{e c}$, and $L_{e c}$ are the radius and lengths of the plasma in the central cell and eno cell, respectively; $P$ is the central cell fusion power density; $f_{\alpha}$ is an alpha confinement factor (see belou); $\pi_{e c}$ is the end cell ion dersity; $T_{c}$ is the central cell ion temperature; $c$ is a constant; and $S$ represents the small subsidiary central cell losees (e.g., radiation losses). The implication of Eq. (1) is clear. As the length (and thus volume) of the end cell magnetic configuration increases, the dimensions of the central cell plasma must increase so that fusion alpha power can make good the power losses due to increased trapping in the end cell. In this regard, a recent study of tandem mirror ignition machines at LLNL, demonstrated that ignition with a MARSlike quadrupole end cell would require a minimum ignition length approximately three times that of a machine with octopole end cells. 5

One is justified to ask at this point why the central cell radius $r_{c}$ cannot be simply increased to meet the ignition criteria with a corresponding reduction in the length $L_{c}$, thus providing a short compact machine. However, besides ignition, the second important design criterion that must be wet is conservation of magnetic flux mapping through the machine, i.e.,

$\pi r_{c}^{2} B_{c}\left(1-\left\langle B_{c}\right)^{1 / 2}=\pi r_{e c}^{2} B_{e c}\left(1-\left\langle B_{e c}\right)^{1 / 2}\right.\right.$

were $B$ represents the vacuum fields and the beta corrections are applied to account for the plasma diamagnetism at high beta. Therefore, asouming that end cell magnetic fielda $\mathrm{B}_{\mathrm{ec}}$ are maintained at their economical maximum, an increase in central cell radius must be matched by a corresponding increase in end cell radius $r_{e c}$ and therefore, by a further increase in end cell trapping volume; this in turn requires a greater central cell length to meet the ignition criteria according to Eq. (1).

Note also that ve cannot minimize end cell volumes by $B$ imply reducing the end cell plasma radius $r$ ec to arbitrarily small values. By Eq. (2), this would resuit in small values of the central cell radius $r_{c}$ vith detrimental effects to alpha deposition efficiency. In our high beta, low field, central cell, the gyroradius of the $3.5 \mathrm{MeV}$ fusion alpha particle is typically an appreciable fraction of the plasma radius. Further reductions in plasma radius would result in increased alpha absorption by the haio outside the core plasma, with a resulting decrease in the alpha confinement parameter $f_{\alpha}$ in Eq. (1).5

Here then lies the probletn with end cell magnetic configurations such as the MARS quadrupoles which have long characteristic lengths. A long end cell length requires a long central cell for ignition making it impossible to achieve small reactor sizes in an economic fashion. By contrast, the octopole provides a method of obtaining a short end cell configuration with a minimum end cell length ( $27 \mathrm{~m}$ ) determined only by sloshing ion adiabaticity, ${ }^{2}$ thus allowing us to consider economic tandem mirror reactors as small as $250 \mathrm{MW}_{e}$. We illustrate this principle in Fig. 3, where the octopole end cell ingnet set for MIN IMARS $\left(600 \mathrm{MW}_{\mathrm{e}}\right)$ is compared with the quadrupole set for MARS $\left(1200 \mathrm{MW}_{e}\right)$.

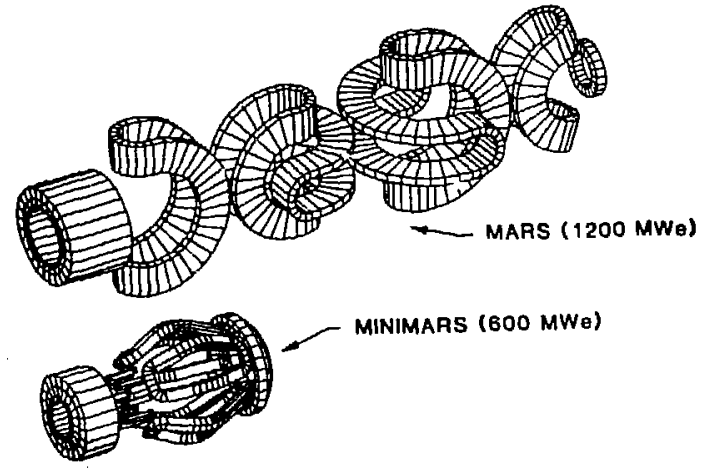

Fig. 3. Comparioon of tile end cell magnetic configurations for MARS and MINIMARS. 
THE OCTOPOLE MAGNETIC CONFIGURATION

Figure 4 is an isometric $v$ iew of the current MIN IMARS end cell magnet set. The outer octopole coil, located between the high field choke coil and the outer mirror coil, is seen to be composed of four discrete coils and represents a distinct improvement over an earlier continuous winding design in terms of accesa and maintenance. An important feature of multipoles having order $N$ greater than $N=4$ for the quadrugole is that the minimum in I BI occurs off the central axis with a period of $\cos (\mathrm{N} \theta / 2)$. Also the near axis multipole field components decrease with increasing $N$, 80 the higher the number of $b a r s$, the more axisymetric the near axis field will be. Since there is a limit to the number of bars due to access requirements, we have proposed an octopole $(N=8)$ configuration for MINIMARS, although we are also assessing hexapole coils $(N=6)$.

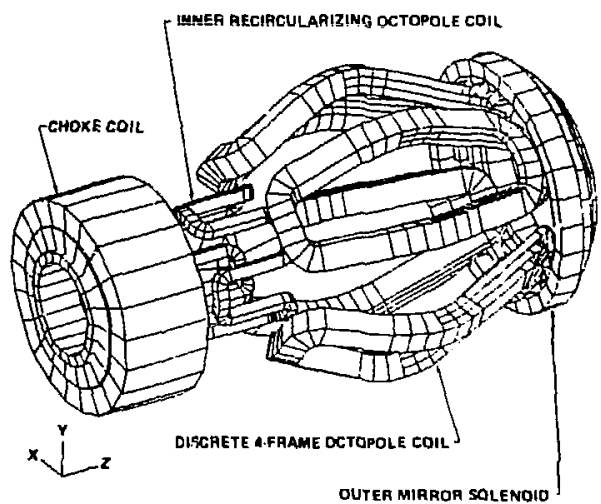

Fig. 4. Details of the MINIMARS end cell magnetic configurations.

The relative magnitudes of the solenoidal mirror fieldo and the octopole field are adjusted to place the minimum $|B|$ point oucside of the core plasma fiux bundle which mapa to the central cell. Any residual non-axisymetry of the flux bundle at the midplane of the octopole can be cancelled by means of the small inner recircularizing octopole coil also shown in Fig. 4. The intervening region between the core plasma and the minimum $|B|$ point is bridged by a "mantle" of mirror-confined hot electrons sustained by an additional ECRH system (see Fig. 2).

Approfriate tailoring of the $r$ ising pressure profile of the mantle electrons ensures MHD atability to flute interchange modes driven by the bad curvature regions of the cencral cell and end cell.2 Stability against interchange does not, of course, guarantee stability to ballooning modes at high $B$. However, FLR phenomena are expected to stabilize all ballooning modes except for $m=1$, while calculations of this mode in quadrupolestabilized tandem mirrors have yielded beta limits very close to those predicted by interchange criteria. ${ }^{2}$ MHD analys is for MINIMARS continues to be a fruitful research area.

While the end cell core plasma is essentially axisynmetric, the mirror-confined hot alectron mantle surrounding the core plasma exhibits the characteristic four-pointed convoluted shape of the octopole field far from the axis. Moreover, the mantla occupies field lines which do not map through the machine. Accordingly, as the study progresses, particular attention will be given to this region regarding ECRH absorption profiles and electron scattering losses.

\section{SYSTEM MODELING AND PARAMETER SELECTION}

The initial phases of the MIN IMARS project have been characterized by extensive parameter searches to elicit plasma engineering baselines which meet the economic objectives discussed above. To this end, we have made considerable use of our Tandem Mirror Systems CodeOptimization Package, which performs plasma modeling, power balance, and systems optimization functions. 6 with this code, we can optimize a user opecified figure of merit [e.g., cost of electricity (mills/kWhr)] subject $L J$ a set of constraints [e.g., fixed net electric output power ( $\left(W_{e}\right)$ ] by variation of up to 26 plasma engineering parameters. Full details are given in a companion paper. 6

Table 1 lists the major plasma engineering parameters for the current MINIMARS baseline at $600 \mathrm{MW}$. Listed for comparison are the equivalent parameters for a $250 \mathrm{MW}_{\mathrm{e}}$ version of MIN IMARS. These parameters are subject to modification as our study matures. Both sets of parameters were determined by the TMSCOptimization Parkage configured for optimized (i.e., minimum) cost of electricity at fixed net electric power. ${ }^{6}$ Notice the high $Q$ value (i.e., fusion power divided by plasma heating power) which illustrates the beneficial nature of compact end cells. Notice slso that optimized design resulta in relatively long central cell lengths with small plasma radius and, therefore, smell end cell volumes with correspondingly low heating powers.

\section{CONCLUS ION}

Thus far in the MINIMARS study we scoped initial design parameters and cost projections for a small tandem mirrar reactor with a net 
Table 1. Principal physics parameters for MINIMARS optinized for cost of electricity.

\begin{tabular}{|c|c|c|}
\hline & $\begin{array}{c}\text { MIN RLARS } \\
\text { at } \\
600 \text { MHe }^{2}\end{array}$ & $\begin{array}{c}\text { MIN IMARS } \\
\text { at } \\
250 \mathrm{MHe}\end{array}$ \\
\hline \multicolumn{3}{|l|}{ General } \\
\hline Fusion power (MW) & 1206 & 553 \\
\hline Q & 78 & 49 \\
\hline $\begin{array}{l}\text { Neutrom wall loading } \\
\left(\mathrm{MW} / \mathrm{m}^{2}\right)\end{array}$ & 2.7 & 1.6 \\
\hline Total capital cost (M\$) & 1066 & 687 \\
\hline $\begin{array}{l}\text { Cost of electricity } \\
\quad(\mathrm{mills} / \mathrm{kWh})\end{array}$ & 56 & 80 \\
\hline $\begin{array}{l}\text { Mass utilization } \\
\text { (kWe/tonne) }\end{array}$ & 65 & 35 \\
\hline \multicolumn{3}{|l|}{ Magnetic fields } \\
\hline Central cell (T) & 2.95 & 2.76 \\
\hline Choke coil (T) & 26.0 & 24.8 \\
\hline End cell midplane (T) & 1.5 & 1.5 \\
\hline Outer mirror ( $T$ ) & 6.6 & 6.9 \\
\hline \multicolumn{3}{|l|}{ Central cell } \\
\hline Length (m) & 94.9 & 75.5 \\
\hline Plasma radius (m) & 0.42 & 0.38 \\
\hline Ion temperature (keV) & 29.2 & 32.4 \\
\hline$\langle\beta\rangle$ & 0.6 & 0.6 \\
\hline \multicolumn{3}{|l|}{ End cell } \\
\hline$\langle\beta\rangle$ & 0.33 & 0.3 \\
\hline Core ECRH power ${ }^{b}$ (MW) & 4.3 & 2.7 \\
\hline Mantle ECRH power ${ }^{b}(\mathrm{MW})$ & 10.9 & 8.4 \\
\hline NBI power ${ }^{b}$ (MW) & 0.28 & 0.19 \\
\hline
\end{tabular}

\footnotetext{
abaseline case.

babsorbed, both ends.
}

electric output of $600 \mathrm{rWe}$. The novel compect octopole end cell of MIN IMARS appears to offer a distinct improvement over the more conventional quadrupole end cell because it permits ignition at much shorter central cell lengths, thus enabling the realization of suall but economic tandem mirror reactors. In addition to extensive parameter trade studies with the Tandem Mirror Systems Code, future plasma engineering tasks vill include further attention to ECRH ray tracing and absorbtion in the mantle, drift pumping in axisyumetric plasma geometries, physics of the plasma halo, fueling, and enhancement of MHD stability and 3 limits with conducting walls.

\section{REFERENCES}

1. B. G. LOGAN et al., Mirror Advanced Reactor Study (MARS) - Final Report, Volume IA and 1B, Lawrence Livermore National Laboratory, Livermore, CA, UCRL-53480 (1984).

2. R. S. DEVGTO, D. E. BALDWIN, B. G. LOGAN, G. W. HAMILTON, and B, H. JOHNSTON, A Smal1 Octopole-Stabilized Tandem Mirror Reactor, Lawrence Livermore National Laboratory, Livermore, CA, UCID-20157 (1984).

3. T. C. SIMONEN et al., "Thermal Barrier Confinement Experiments in the TMX-U Tandem Mirror," Proc. 10th IAEA Intl. Conf. on Plasma Physics and Controlled Fusion Research, London, England (1984).

4. R. R. BORCHERS and C. M. VAN ATTA, The National Mirror Fusion Program Plan, Lawrence Livermore National Laboratory, Livermore, CA, UCAR-10042-80 (1980).

5. J. D. LEE (Ed.) et al., Fusion Power Demonstration (FPD) III, Lawrence Livermore National Laboratory, Livermore, CA, UCID-19975-2 (to be published 1985).

6. R. B. CAMPBELL, D. T. BLACKF IELD, and L. J. PERkTNS, "Phys ics-Magnetics Trade Studies for Tandem Mirror Reactors," Proc. of 6 th Top. Mtg. on Technology of Fusion Energy, San Francisco, CA, March 1984, submitted to Nuclear Technology. 